\title{
Robótica Educacional de Baixo Custo: Arduino como Ferramenta Pedagógica
}

\author{
Daniel Scherer $^{1}$, Natanael Bezerra da Silva ${ }^{2}$, Davis Matias de Oliveira ${ }^{2}$
}

${ }^{1}$ Departamento de Computação - Universidade Estadual da Paraíba (UEPB)

R. Baraúnas, 351 - Universitário, Campina Grande - PB, 58429-500

${ }^{2}$ Departamento de Matemática - Universidade Estadual da Paraíba (UEPB)

R. Baraúnas, 351 - Universitário, Campina Grande - PB, 58429-500

\{scherer, davis_matias\}@servidor.uepb.edu.br, natanaelbs@gmail.com

\begin{abstract}
Robotics has almost its own attraction to gather people. With the possibility of moving a piece of equipment, either via programming or even via control (remote or via smartphone), robotics attracts looks and directs the desire to interact. In the case of students, regardless of age, it is no different. Unfortunately, in Brazil, the cost of accessing robotic materials, whether of a purely recreational nature or of educational potential, is usually not inviting. In this sense, there is the option of low-cost and often open-source materials, such as the Arduino platform. However, its use sometimes requires knowledge to use and assemble parts and components, to have electronics skills (to effectively build a robot) until it reaches the programming point of the created robot. This work presents a vision of using low cost robotics based on the Arduino platform, and a discussion of the reasons that led the evolution of the robot created in mid-2012, costing $R \$ 228.00$ at the time, for a new version costing $R \$ 145,00$.
\end{abstract}

Resumo. A robótica possui quase um atrativo próprio para aglomerar pessoas. Com a possibilidade de movimentar um equipamento, seja via programação ou mesmo via controle (remoto ou via smartphone), a robótica atrai olhares e direciona a vontade de interagir. No caso de alunos, não importando a idade, não é diferente. Infelizmente, no Brasil, o custo para acesso a materiais robóticos, sejam de cunho puramente recreativo ou de potencial educacional, habitualmente, não é convidativo. Neste sentido, tem-se a opção dos materiais de baixo custo e muitas vezes open-source, a exemplo da plataforma Arduino. Entretanto, seu uso, por vezes, demanda conhecimentos para usar e montar as peças e componentes, ter habilidades de eletrônica (para efetivamente construir um robô) até chegar ao ponto da programação do robô criado. Este trabalho apresenta uma visão de uso de robótica de baixo custo baseado na plataforma Arduino, e uma discussão dos motivos que levaram a evolução do robô criado em meados de 2012, custando na época $R \$ 228,00$, para uma nova versão custando $R \$ 145,00$.

\section{Introdução}

A tecnologia permeia cada vez mais o cotidiano das pessoas. Há um número crescente de aparelhos celulares em conexão com a Internet e possibilidades de execução de aplicativos. A popularização de meios computacionais foi possível, principalmente, devido ao barateamento da tecnologia para sua construção. Interessante observar que a 
robótica, apesar de contemporânea e até mesmo predecessora do uso de ferramentais computacionais (vide os primeiros esforços educacionais de Papert (2008), ainda hoje desponta como sendo uma inovação e, normalmente de potencial pouco aproveitado.

Segundo Malec (2001), desde 1980, a robótica é utilizada de muitas formas no processo de ensino/aprendizagem; tanto a nível fundamental, quanto no ensino médio e superior. $\mathrm{O}$ autor indica que o uso da robótica no meio educacional pode ser classificado segundo dois princípios:

- Robótica na educação: como uma forma divertida de trabalhar ciência e engenharia de forma lúdica;

- Robótica para educação: como uma ferramenta educacional útil no processo educativo de ensinar os conteúdos que precisam ser trabalhados.

Ainda segundo Malec (2001), sobre como a robótica é utilizada principalmente no ensino médio, tem-se as seguintes perspectivas:

- Projeto: a maioria dos cursos levam os estudantes a realizarem as etapas de planejamento de projeto;

- Trabalho em equipe: uma vez que a robótica permite que os alunos exercitem o trabalho em equipe para alcançar os objetivos do projeto (sendo, portanto, uma estratégia conjunta com a de projeto);

- Curso introdutório em Engenharia Elétrica (ou Computação): em que construir um robô não é o objetivo do projeto, mas sim o meio para o aprendizado dos conceitos básicos de computação e eletrônica, uma vez que possibilita ver concretamente os resultados dos algoritmos criados.

Inicialmente, o potencial educacional que a robótica proporciona está diretamente ligado às ferramentas empregadas para o trabalho em ambientes educacionais, tal como exposto por Azevedo et al. (2010). O uso de kits facilita o processo de construção de robôs, em especial para um público de iniciantes, sendo, portanto, muitas vezes considerada a melhor alternativa para escolas que desejam implantar a robótica como ferramenta pedagógica.

Robôs são compostos por peças, tais como: controlador, sensor(es), atuadores, manipuladores, engrenagens, eixos, fonte de energia, fiação e estrutura. Para a programação de robôs, os kits podem utilizar uma linguagem proprietária, desenvolvida especificamente para cada kit ou utilizar linguagens abertas, tal como $\mathrm{C}++$. Ainda com relação as linguagens, elas podem ser gráficas (baseadas em ícones) ou podem utilizar construções por meio de texto. Além desses elementos, ainda existem materiais que auxiliam na utilização do kit, tais como: manuais do usuário, documentação técnica e material de apoio pedagógico para suporte ao professor.

Este artigo busca, a partir da exposição de kits de robótica comerciais e kits de robótica de baixo custo, analisar a nova versão do kit de robô Praxedes. São apresentadas as mudanças realizadas em prol da facilidade de montagem e manuseio do kit. Também são discutidas a relação de peças componentes do Kit e diferenças frente a versão original de 2012, Praxedes 1.0. Desta forma o artigo está organizado da seguinte maneira: na Seção 2 são apresentadas as bases teóricas que norteiam a abordagem utilizada pelo grupo para aprimorar o kit de robô Praxedes; na Seção 3 é apresentada uma discussão sobre os kits comerciais; em seguida, na Seção 4, é feita uma discussão sobre robótica Open 
Source; na Seção 5 é feita uma discussão sobre o robô Praxedes e; por fim, na Seção 6, são feitas as considerações finais.

\section{Fundamentação Teórica}

A sala de aula deveria ser um campo fértil para a criatividade do professor. Podemos citar como exemplo as possibilidades que os laboratórios de matemática, física e química poderiam fornecer para aulas mais interativas, motivadoras e dinâmicas. Entretanto, sabese que são poucas as escolas que possuem tais ferramentas. Paralelamente, tem-se os smartphones invadindo o espaço da sala de aula, mas sem uma coerência sólida com teoria educacional.

Já no cenário da robótica educacional, diversos pesquisadores formalizam suas teorias de ensino e aprendizagem como forma de melhorar a transferência do conhecimento. Podemos apontar o Construtivismo de Jean Piaget e a Teoria das Inteligências Múltiplas de Howard Gardner como uma espécie de precursoras. Ambas encontram eco no uso de robótica educacional. Obviamente a primeira possui mais força, provavelmente pelos esforços empreendidos por Seymour Papert e sua proposta de informatizar a sala de aula [Papert 2008].

\subsection{Construtivismo (Jean Piaget) [Piaget 2016]}

O construtivismo é uma tese epistemológica que defende o papel ativo do sujeito na criação e modificação de suas representações do objeto do conhecimento. Desenvolvida por Jean Piaget em 1967, a tese foca no conhecimento científico das crianças ou daquele que está aprendendo. A tese está organizada em compreender as etapas da evolução do aprendizado desde a criança nos seus primeiros anos de vida até sua fase adulta, classificando essas fases das inteligências como estágios.

O construtivismo considera que há uma relação do conhecimento, no qual, a educação deverá criar métodos que estimulem a criatividade do educando. Desse modo o educador é uma ferramenta importante na inovação das aulas. Portanto, Piaget classifica essa evolução em etapas:

- Sensório-Motor (0 - 2 anos): O indivíduo desenvolve a capacidade de reconhecer a existência de um mundo externo. Passando a agir não apenas por reflexo, mas com o comportamento para alcançar seus objetivos;

- Operacional pré-operatório (2 - 7 anos): A criança elabora e organiza seu mundo por intermédio de esquemas padrões de respostas para eventos que ainda não possui subsídios para compreender e explicar;

- Operacional concreto (7 - 12 anos): Nessa fase, a criança começa a lidar com conceitos como os números e relações. Esse estágio passa a manifestar-se de modo mais evidente o que coincide (ou deve coincidir) com o início da escolarização formal, ou seja, com o Ensino Fundamental. É caracterizado por uma lógica interna consistente e pela habilidade de solucionar problemas concretos;

- Operacional formal ou abstrato (12 - 15 anos e na vida adulta): adquirir pensamento operatório formal e a capacidade de construir provas lógicas em que a conclusão segue a necessidade lógica. Essa habilidade constitui o raciocínio dedutivo. 


\subsection{Teoria das Inteligências Múltiplas (Howard Gardner) [Gardner 2002]}

Em 1980, na Universidade de Harvard, foi desenvolvida por uma equipe de investigadores liderada pelo psicólogo Howard Gardner, uma teoria denominada Inteligências Múltiplas, a qual buscava analisar e descrever melhor o conceito de inteligência. Os autores apontavam que o conceito de inteligência, como tradicionalmente era conhecido em psicometria (testes de QI), não era suficiente para descrever as habilidades cognitivas humanas. $\mathrm{O}$ foco da pesquisa foi a manifestação das múltiplas inteligências que compõem os aspectos das competências pedagógicas, que incluem: a linguística, lógica matemática, musical, espacial (capacidade de visualização espacial de um objeto), cinestésica (capacidade de manipular os objetos e controlar movimentos do corpo), interpessoal (capacidade de dar uma resposta ao estado de humor) e intrapessoal (habilidade de acessar os próprios sentimentos).

\subsection{Informática, Piaget e Gardner: Robótica Educativa}

Ambos Piaget (2016) e Gardner (2002) tinham aspirações no uso da computação para fins educacionais, principalmente pelo potencial do computador repetir infindavelmente uma mesma instrução sem questionamentos. Assim, "pelo fato de ser multidisciplinar, permitir que o aluno seja um ser ativo, que resolva situações-problemas, disponibilizar os mais variados recursos para solucionar esses problemas" do Rocio Zilli (2004), o computador poderia ter grande potencial de aplicação em sistemas de ensino. Para Gardner, havia um uso mais tecnicista e direcionado. Já Piaget, quando trabalhou em conjunto com Papert entre 1959 e 1963 na Universidade de Genebra, conseguiu resultados promissores no uso de dispositivos robóticos controlados por um painel (Figura 2B) ou, mais tarde, por um computador. Pode-se observar que os alunos, através do uso de tais recursos tecnológicos podiam ter um aprendizado aprimorado, principalmente por embasarem-se em quatro pontos (Figura 1).

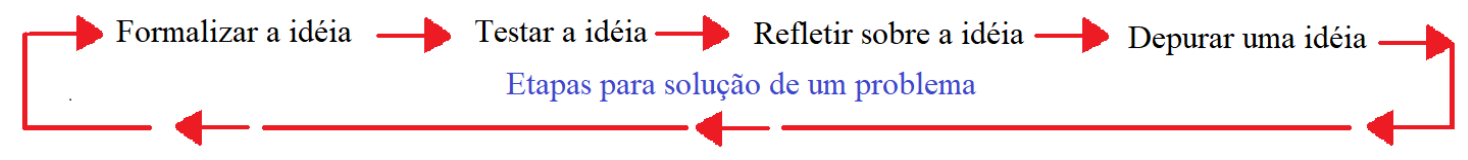

Figura 1. Fases de interação

Desse modo, Papert (2008) junto a outros professores do MIT (Instituto de Tecnologia de Massachusetts), desenvolveram a primeira versão da linguagem Logo, na qual podemos considerar uma das primeiras aplicações da psicologia cognitiva no ambiente educacional da informática, funcionando com a primeira versão da tartaruga programável (Figura 2A).

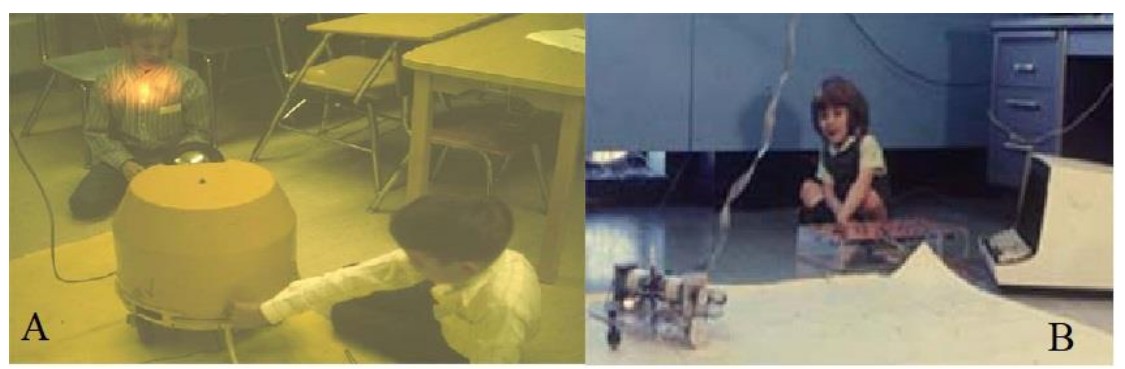

Figura 2. Primeiros robôs educacionais programáveis. 


\section{Kits de robótica educacional}

Com a evolução dos robôs programáveis houve a expansão da composição dos kits, que podem ser compostos pelos seguintes conjuntos de elementos:

\section{Peças de hardware:}

- Componentes estruturais: são as partes que compõem a estrutura física dos kits, engloba desde seus manipuladores (braços e garras), rodas, até bases para fixação de outras peças;

- Componentes eletrônicos: possibilitam a adição de recursos de movimento (motores) e permitem a interação do robô com o ambiente (dispositivos sonoros, visuais e sensores);

- Unidade programável: nesta categoria estão inseridos os microcontroladores da parte central de um robô, que permitem embutir uma programação a ser executada.

\section{Software:}

- Linguagem de programação textual: engloba tanto linguagens tradicionais (Delphi, Java ou $\mathrm{C}++$ ), como também linguagens exclusivas, como a utilizada nos produtos Arduino;

- Linguagem de programação gráfica: cuja construção de programas é baseada em arrastar e soltar ícones e outros elementos gráficos como, por exemplo, ocorre com a interface do Lego Mindstorms.

\section{Material de apoio:}

- Material de apoio pedagógico: material de apoio ao professor, tradicionalmente composto por exemplos de projetos possíveis de serem feitos com cada kit;

- Manual do usuário: material tradicional que apresenta a relação de peças disponíveis no kit, bem como instruções para instalação e manipulação do software;

- Documentação técnica: material abrangendo dados técnicos, normalmente visando viabilizar a confecção de componentes extras ou de implementações mais avançadas.

Atualmente há uma variedade grande de kits de robótica educacional, os quais possuem suas próprias linguagens de programação ou utilizam outras linguagens já existentes no mercado; se utilizam, também, de peças próprias da linha (como observado nos kits da Lego), ou de sucata e componentes eletrônicos (como kits considerados open source). Muitos desses kits variam de custo, sendo a grande maioria financeiramente inviável para uso nas escolas públicas e, assim, acentuando a desigualdade social. Os kits mais utilizados para ensino através da robótica educacional normalmente são:

- LEGO Mindstorms: após a parceira de Seymour Papert com a empresa de brinquedos LEGO em 1980, começam a surgir os primeiros kits de robótica educacional. A parceria entre a Media Lab do Massachusetts institute of Technology (MIT) e o LEGO Group, desenvolvem o produto LEGO Mindstorms, que é constituído por um conjunto de peças da linha tradicional (tijolos, placas, rodas) e a da linha LEGO Technic (tijolos vazados, motores, eixos, engrenagens polias e correntes), acrescidos de sensores de toque, de luminosidade, e de temperatura, controlados por um processador programável - o módulo RCX 
(Robotic Command Explorer) - ou operado por controle remoto (com ou sem fio). Custo Kit STEM: \$349,99 [Group. 2019];

- OWIKTI: em 1980, a OWI Incorporated procurava uma maneira de expandir suas linhas de produtos de consumo e trazer sua extensa experiência em tecnologia para a comunidade educacional. RobotiKits ${ }^{\mathrm{TM}}$ e OWIKits ${ }^{\circledR}$ foram desenvolvidos para apresentar aos alunos a tecnologia robótica de maneira acessível. Cabe observar que tais kits permitem a montagem de apenas um modelo em particular, normalmente sem condições de programação e, habitualmente, operado por um controle. Custo Kit STEM: \$39,95 (sem programação) [Direct 2020];

- K'NEX Education: um dos kits mais completos da linha K'NEX inclui mais de 800 peças K'NEX, uma caixa de controle, 4 motores, 1 sensor de botão de pressão, 1 sensor de distância, 1 LED tricolor e 1 sensor de cor / luz. O kit também pode ser encontrado na forma de conjuntos de educação K'NEX, que vem com planos de aula e guias de experiências com projetos práticos baseados em perguntas. Cabe observar que a vertente principal da linha K'NEX é a disponibilização de peças plásticas conectáveis para montagem de estruturas, por exemplo, montanha russa, roda gigante e pontes. Custo Kit STEM: £112,90 [K'NEX 2020];

- Meccano Robotic Education: os kits podem conter componentes eletrônicos reais, tais como um sensor infravermelho e um motor de alto torque para que, assim, sejam construídos carros motorizados e robôs. O kit de Meccano Robotics Education é composto por peças estruturais de metal, conectadas a partir de porcas e parafusos (permitindo assim o uso de materiais recicláveis). Novamente cabe observar que a vertente principal de produtos da Meccano é a montagem de modelos de veículos e estruturas de construção, com forte apelo a Engenharia. Custo Kit STEM: \$74,38 (sem programação) [Meccano 2020];

- Modelix Educacional: é um kit que inclui uma variedade grande de peças (normalmente de metal) e conectáveis por porcas e parafusos. O kit é direcionado ao aluno do ensino fundamental e médio, com forte apelo ao STEM (Ciências, tecnologia, engenharia e matemática). O fabricante do Modelix possui materiais de apoio e um software para programação do bloco programável (que é bastante parecido com o Arduino). Assim como o Meccano, o fato de usar peças metálicas, porcas e parafusos acaba facilitando a incorporação de materiais recicláveis. Custo Kit STEM: R\$3.200,00 [Robotics 2020];

- Horizon Education: é um kit para trabalho de STEM no campo de incentivo de energias renováveis. Existem kits compostos por uma turbina em miniatura que funciona tal como em escala real, um painel solar fotovoltaico, um eletrolisado, uma célula a combustível de tecnologia PEM, um sistema de armazenamento de hidrogênio, motor elétrico e, LEDs para aplicações iniciais. Quando passível de programação, utiliza-se do Arduino UNO. Custo Kit STEM: 1.199,00 [Horizon Fuel Cell Europe 2020];

- Robot Edison: é um kit para implementação de robótica nas escolas composto por um bloco de programação baseado em um processador de 8 Bits (Freescale 8bit MC9S08PA16VLC). O bloco básico já contém sensor IR, seguidor de linha, sensor de som, dois motores embutidos. Possui interface de programação visual e textual (todas específicas para o robô Edison). A comunicação entre computador e o robô é feito por cabo específico. Um ponto interessante sobre o robô é que ele permite a conexão com peças do tipo LEGO Technic, sendo que o custo do Kit STEM é \$114,00 [Microbric. 2020]. 


\section{Open Source como ferramenta pedagógica}

O custo desses kits para escolas públicas, normalmente possuem alto valor, o que tende a torná-los inacessíveis. Uma alternativa vem a ser o uso de ferramentas de softwares livres e hardware aberto. Uma das formas mais acessíveis pode ser o uso do Arduino. O Arduino é uma plataforma de prototipagem eletrônica de placa única, projetada como um microcontrolador Atmel AVR com suporte de entrada/saída embutido, com uma linguagem de programação padrão open source. Pode ser usado para desenvolvimento de objetos interativos ou ainda para ser conectado a um computador. O projeto iniciou-se na cidade Ivrea em 2005, com a intenção de interagir com projetos escolares de forma a ter um orçamento menor que outros sistemas de prototipagem disponíveis na época [Arduino2020].

A vantagem do Arduino é a interação com outros componentes encontrados facilmente no mercado, tais como LED, Sensores de luminosidade, sensores ultrassônicos, motores AC/DC, conectividades Wifi, bluetooth e USB. De contraponto, o uso se torna mais complexo devido a necessidade de conhecimentos em eletrônica básica e circuitos lógicos. Para tornar a Open Source uma ferramenta pedagógica eficaz e acessível para escolas, focamos na construção básica de um robô Praxedes, composto por LEDs, sensores, ponte $\mathrm{H}$, motores DC com caixa de redução, rodas e, a placa Arduino Uno.

\section{Praxedes versões 1.0 e 2.0}

A busca por tornar realidade o ensino com auxílio de robótica educacional nas escolas públicas levou ao desenvolvimento do projeto denominado Praxedes, cujo objetivo central era a redução do custo do Kit de robótica aliado a proposta de um kit único e fácil de operar. Este kit foi obtido através da plataforma Arduino em conjunto com alguns componentes eletrônicos de fácil aquisição.

\subsection{Praxedes 1.0}

O Praxedes 1.0 foi concretizado como Trabalho de Conclusão de Curso em 2012. Considerando a premissa de um kit de baixo custo. Muitos de seus componentes eram totalmente confeccionados a partir de componentes elementares, a exemplo do sensor de luminosidade e da ponte $\mathrm{H}$. Outros componentes eram advindos de sucata de brinquedos como, por exemplo, as rodas; ou mesmo de tábuas de carne, utilizadas para a confecção do chassi. O custo de construção do Praxedes foi de R \$224,80. Entretanto, percebeu-se que a completa construção do robô exigia conhecimentos em eletrônica básica para a confecção do sensor e ponte $\mathrm{H}$, bem como demandava acesso a equipamentos de corte e montagem. Isto levou a problemas com fragilidade do protótipo, o tornando mais sensível a impactos e mal contato entre seus componentes.

\subsection{Praxedes 2.0}

O Praxedes 2.0 traz uma atualização no material utilizado para construção. Com o avanço da tecnologia e expansão do mercado maker, apareceram novos componentes mais robustos e mais baratos. Diferente da primeira versão, o uso de um shield ponte H L298N para o controle dos dois motores DC é uma escolha viável pois evita os problemas com a soldagem de um circuito eletrônico. Também, o uso de baterias modelo 18640 com o intuito de aumentar a performance de energia do robô, bem como tornar mais fácil as suas 
recarregas. Cabe observar, ainda, que se encontra em estudo a nova sistemática para a utilização do sensor de luminosidade.

\subsection{Comparativo entre versões}

Houveram modificações na estrutura do robô para torná-lo mais resistente, bem como, houve a atualização da fonte de energia para aumentar a autonomia de uso e a facilidade de sua recarga. A modificação dos motores buscou fornecer um controle maior no deslocamento efetuado pelo robô, uma vez que agora há dois motores completamente independentes e, possibilitar a redução de seu custo (Tabela 1). Outro ponto a ser observado é que a versão 2.0 ainda não possui novo conjunto de sensor de luminosidade, mesmo o novo circuito já existindo. Isto se deve aos esforços focados nos experimentos com os novos motores e sensor de ultrassom.

Tabela 1. Tabela de comparativo entra as versões

\begin{tabular}{|l|c|c|}
\hline \multicolumn{1}{|c|}{ Componente } & Praxedes 1.0 & Praxedes 2.0 \\
\hline Processamento & Arduino Duemilanove & Arduino Uno \\
\hline Motores & Motor duplo Tamiya & Motor DC 3-6v com caixa de redução \\
\hline Terceira roda & Roda Pololu & Roda boba \\
\hline Rodas & Rodas de Boracha de carrinho & Rodas de Borrachas para Projeto de Arduino \\
\hline Bateria & Bateria de 9v & Bateria recarregavel 18650 \\
\hline Controle de motores & Circuito impreso com Cl L293D & Shield Ponte H L298N \\
\hline Chassi & Placa de Acrilico Moldada & Chassi Carro de Acrilico para Arduino \\
\hline Sensor ultrasonico & HC-SR04 & HC-SR04 \\
\hline Sensor iluminação & LED e LDR & - \\
\hline Outros Componentes & Jumper Macho Macho & R $\$ 145,00$ \\
\hline Total & R $\$ 238,80$ & Jumper Macho Macho \\
\hline
\end{tabular}

\section{Considerações finais}

Neste artigo buscou-se apresentar a nova versão do robô Praxedes. O robô Praxedes foi desenvolvido como uma alternativa para Robótica Educativa na prática. Para isto, ele tem como premissas:

- usar componente de programação que permita amplo acesso, tanto em termos de custo de aquisição quanto de formas de programação;

- possuir uma estrutura de montagem que seja economicamente acessível;

- primar por facilidade de construção, buscando a menor exigência possível de conhecimentos de eletrônica;

- ser um bloco estável que não demande inclusões de novos recursos para serem utilizados e, assim, possa ser intercambiável entre turmas diferentes.

Particularmente sobre este último item, cabe ressaltar que uma dificuldade característica observada na aplicação de robótica em sala de aula, vem a ser que:

- os alunos acabam ocupando tempo considerável da aula na montagem dos Kits; por exemplo, para montar um carrinho motorizado;

- o Kit montado, ao final da aula, precisa ser desmontado para que a turma seguinte possa ter sua aula de robótica; 
- o professor, não necessariamente, possui conhecimentos sobre a montagem dos Kits;

- percebe-se pelos experimentos do grupo de pesquisa Informática Educativa da Paraíba que uma estrutura única (bloco estável que não demande inclusões de recursos) proporciona amplas possibilidades de interações e aplicações de conteúdos programáticos.

Com os atuais experimentos realizados no grupo percebe-se que os aprimoramentos realizados no Praxedes estão em consonância com as demandas de aplicação em sala de aula para abordagem de conteúdos programáticos; por exemplo, na disciplina de matemática.

Observando-se os demais Kits voltados para Robótica Educacional, o robô Edison é o que mais tem similaridade com o robô Praxedes. Ambos partem de uma base única: robô em forma de carro com três rodas, dois motores e sensores embutidos.

O robô Edison apresenta possibilidades de uso de peças estruturais LEGO Technic, porém a ideia do grupo é que o robô seja usado na sua forma original sem demandar construções extras e exigir desnecessariamente tempo de sala de aula e/ou conhecimentos do professor. Outro ponto a ser observado é o custo: o robô Edison, na versão STEM vem com 2 robôs e custa $\$ 114,00$ (convertidos em Reais, ficando por volta de $\mathrm{R} \$ 590,00)$. Já o Praxedes fica com um custo, para dois robôs, de $\mathrm{R} \$ 290,00$. Considerando-se que, habitualmente, são necessários de 5 a 6 kits para aplicação de robótica em sala de aula, com até 6 grupos de alunos (normalmente 5 alunos por grupo) simultâneos (Tabela 2). Cabe observar que os kits da OWIKIT e da Meccano não foram incluídos por não ter sido possível encontrar valor dos kits com componente de programação.

Como trabalhos futuros, tem-se a continuidade dos experimentos com os novos componentes; inclusão do componente de luminosidade; expansão das análises de aplicação de conteúdo programático de sala aula com o uso do robô (matemática do ensino médio, matemática do ensino fundamental II, física do ensino médio).

\section{Referências}

Arduino (2020). “Arduino". Disponível em https://www.arduino.cc/. Acessado em 29 de maio de 2020.

Azevedo, S., Aglaé, A., and Pitta, R. (2010). Minicurso: Introdução a robótica educacional. SBPC. página 41.

By Meccano, E. (2020). "Welcome to erector by meccano. The original inventor brand!". Disponível em http://www.meccano.com/. Acessado em 29 de maio de 2020.

Direct, R. (2020). “Owikit'. Disponível em https://owirobot.com/new/. Acessado em 29 de maio de 2020.

Do Rocio Zilli, S. (2004). "A robótica educacional no ensino fundamental: perspectivas e prática". Master's thesis, Universidade Federal de Santa Catarina, http://repositorio.ufsc.br/xmlui/handle/123456789/86930.

Gardner, H. (2002). Estruturas da mente: a teoria das inteligências múltiplas. Editora Artes Médicas Sul. 
LEGO Group. (2019). "Developer kits". Disponível em https://education.lego.com/enus/support/mindstorms-ev3/developer-kits. Acessado em 29 de maio de 2020.

Horizon Ful Cell Europe, s. (2020). "Stem kits”. Disponível em https://www.horizoneducational.com/stem-kits/c1023. Acessado em 29 de maio de 2020.

K'Nex (2020). “K'nex where criativity clicks”. Disponível em http://www.knex.co.uk/stem-building-toys. Acessado em 29 de maio de 2020.

Malec, J. (2001). "Some thoughts on robótics for education". Proceeding of AAAI Spring Symposium on Robotics and Educaion, página 4.

Microbric. (2020). "Edison programmable robots". Disponível em https://meetedison.com/. Acessado em 29 de maio de 2020.

Papert, S. (2008). A máquina das crianças: repensando a escola na era da informática. Editora Artmed.

Piaget, J. (2016). L'epsitemolia genética. Edizioni Studium Srl.

Robotics, M. (2020). "Modelix robótica educacional". Disponível em https:/www.modelix.com.br/. Acessado em 29 de maio de 2020.

Silva, F. I. d. "Análise de kits de robótica educacional e elaboração de um kit protótipo de custo acessível baseado na plataforma Arduino". Trabalho de Conclusão de Curso. UEPB. 